\title{
Kajian Teori Ideal Perluasan Subtraktif Pada Semiring Ternari
}

\author{
Nur Qomariah dan Dian Winda Setyawati \\ Jurusan Matematika, Fakultas Matematika dan Ilmu Pengetahuan Alam, \\ Institut Teknologi Sepuluh Nopember (ITS) \\ Jl. Arief Rahman Hakim, Surabaya 60111 Indonesia \\ $e$-mail: dian_ws_math@matematika.its.ac.id
}

\begin{abstract}
Abstrak - Pembahasan mengenai teori ideal terus berkembang, salah satunya adalah teori ideal pada semiring ternari. Pada jurnal ini, dikaji mengenai karakteristik ideal-ideal pada semiring ternari $\mathbb{Z}_{0}^{-} \times \mathbb{Z}_{0}^{-}$yaitu ideal utama, Q-ideal, ideal subtraktif, dan ideal perluasan subtraktif. Bentuk-bentuk ideal tersebut memiliki hubungan dengan bentuk-bentuk ideal pada semiring $\mathbb{Z}_{0}^{+} \times \mathbb{Z}_{0}^{+}$. Selanjutnya dengan menggunakan keterkaitan antara ideal perluasan subtraktif dengan Q-ideal, maka juga dikaji mengenai ideal perluasan subtraktif terkecil pada semiring ternari. Selain itu, juga dikaji mengenai ideal prima pada semiring ternari terhadap semiring ternari faktor.
\end{abstract}

Kata Kunci-ideal perluasan subtraktif, ideal prima, semiring ternari, semiring ternari faktor.

\section{PENDAHULUAN}

A LJABAR merupakan salah satu bagian dari ilmu matematika yang mempelajari tentang sifat dan struktur pada suatu himpunan. Struktur aljabar membahas tentang himpunan tak kosong dengan satu operasi biner atau lebih dan memenuhi aksioma tertentu. Salah satu struktur aljabar yang dipelajari adalah semiring. Konsep dari semiring diperkenalkan oleh H.S Vandiver pada tahun 1934 yang sebelumnya pada tahun 1932 Lehmer telah memperkenalkan adanya suatu operasi terner pada struktur aljabar. Pada tahun 1971, W.G Lister [1] memperkenalkan operasi terner pada ring yang kemudian disebut dengan ring ternari. Semiring pun mengalami perkembangan saat Dutta dan Kar [2] memperkenalkan macammacam semiring ternari dan sifat-sifatnya pada tahun 2003.

Telah banyak penelitian terdahulu mengenai konsep ideal pada semiring ternari. Dutta dan Kar [2] menyelidiki karakteristik dari ideal pada semiring ternari. S.Kar [4] melakukan penelitian tentang teori ideal pada semiring ternari $\mathbb{Z}_{0}^{-}$. Chaudhari dan Ingale [3] juga melakukan penelitian mengenai Q-ideal dan ideal subtraktif pada semiring ternari. Selain itu, Chaudhari dan Bonde [6] mengenalkan konsep ideal perluasan subtraktif pada semiring. Selanjutnya, Chaudhari dan Ingale [5] melakukan penelitian dengan mengembangkan konsep ideal perluasan subtraktif pada semiring ke dalam semiring ternari. Pada bagian analisis dan pembahasan dalam jurnal ini, penulis melakukan kajian mengenai teori ideal perluasan subtraktif pada semiring ternari yang dirujuk dari penelitian Chaudari dan Ingale dengan judul "Subtractive Extension of Ideals in Ternary Semirings"[5].

\section{TINJAUAN PUSTAKA}

Himpunan tak kosong $S$ terhadap operasi biner pada penjumlahan $(+)$ dan operasi terner pada perkalian $(\cdot)$ dinamakan semiring ternari, apabila :

a. Bersifat asosiatif dan komutatif terhadap operasi biner pada penjumlahan $(+)$.

b. Bersifat asosiatif terhadap operasi terner pada perkalian () .

c. Terdapat elemen $0 \in S$ yang memenuhi $a+0=0+a$ dan $a \cdot b \cdot 0=a \cdot 0 . b=0 . a \cdot b=0$.

d. Bersifat distributif terhadap operasi biner pada penjumlahan dan operasi terner pada perkalian $(\cdot)$.

Jika terdapat $e \in S$ yang memenuhi e.e. $x=e . x . e=$ $x . e . e=x, \forall x \in S$, maka $e$ adalah elemen identitas pada semiring ternari. Jika untuk setiap $a, b, c \in S$ memenuhi $a . b . c=a . c . b=c . a . b, \forall a, b, c \in S$, maka $S$ dinamakan semiring ternari komutatif.

Perbedaan antara semiring dan semiring ternari terletak pada banyaknya operasi yang berlaku. Semiring disertai dengan dua operasi biner yaitu penjumlahan (+) dan perkalian ('), sedangkan semiring ternari disertai dengan operasi biner pada penjumlahan $(+)$ dan operasi terner pada perkalian $(\cdot)$. Dari definisi tersebut diperoleh bahwa setiap semiring adalah semiring ternari dan tidak berlaku sebaliknya. Semiring $\left(\mathbb{Z}_{0}^{+},+\right.$, ) merupakan contoh semiring ternari, sedangkan semiring ternari $\left(\mathbb{Z}_{0}^{-},+, \cdot\right)$ bukan merupakan semiring. Sebab jika $a, b \in$ $\mathbb{Z}_{0}^{-}$maka pada operasi biner perkalian $a . b \notin \mathbb{Z}_{0}^{-}$.

Berikut merupakan definisi mengenai ideal pada semiring ternari:

Definisi 2.1[5]. I merupakan ideal pada semiring ternari $S$ jika untuk setiap $a, b \in I$ dan $r, s \in S$ memenuhi:

(a) $a+b \in I$, dan

(b) r.s.a, r.a.s, a.r.s $\in I$.

Selanjutnya, diberikan definisi dan lemma mengenai beberapa jenis ideal yang ada pada semiring ternari sebagai berikut :

Definisi 2.2[5]. Jika $S$ adalah semiring ternari dan untuk sebarang $x \in S$ yang dinotasikan $\langle x\rangle=\{m n x \mid m, n \in S\}$, maka $\langle x\rangle$ dikatakan ideal utama dari $S$ yang dibangun oleh $x$.

Contoh 2.3. Himpunan $\langle-3\rangle=\left\{-3 k \mid k \in \mathbb{Z}_{0}^{+}\right\}$merupakan contoh ideal utama pada semiring ternari $\left(\mathbb{Z}_{0}^{-},+, \cdot\right)$. 
Definisi 2.4[5],[7]. Ideal I dinamakan ideal subtraktif pada semiring (semiring ternari) $S$ jika $x, x+y \in I$ dan $y \in S$, maka $y \in I$.

Contoh 2.5. Ideal $\langle-2\rangle$ pada semiring ternari $\left(\mathbb{Z}_{0}^{-},+, \cdot\right)$ adalah ideal subtraktif. Namun, ideal $\langle-2,-3\rangle=\mathbb{Z}_{0}^{-}-\{-1\}$ bukan merupakan ideal subtraktif pada semiring ternari $\left(\mathbb{Z}_{0}^{-},+, \cdot\right)$ sebab $-2+-1=-3 \in\langle-2,-3\rangle$ tetapi $-1 \notin\langle-2,-3\rangle$.

Definisi 2.6[5]. Ideal I dinamakan ideal prima pada semiring ternari $S$ jika untuk setiap $a, b, c \in S$ yang memenuhi a.b.c $\in$ $I$, maka $a \in I$ atau $b \in I$ atau $c \in I$.

Definisi 2.7[5]. Ideal I dinamakan Q-ideal pada semiring (semiring ternari) $S$ jika terdapat himpunan bagian $Q$ pada $S$ sedemikian hingga :

(a) $S=\bigcup\{q+I: q \in Q\}$

(b) Jika $q_{1}, q_{2} \in Q$, maka $\left(q_{1}+I\right) \cap\left(q_{2}+I\right) \neq \varnothing \Leftrightarrow q_{1}=$ $q_{2}$.

Lemma 2.8[3]. Misalkan I merupakan ideal dari semiring ternari $S$ dengan $r, s \in S$ dan $a, x \in S$ sedemikian hingga $a+$ $I \subseteq x+I$, maka:

(a) $a+r+I \subseteq x+r+I$

(b) $r . s . a+I \subseteq$ r.s. $x+I$

(c) r.a.s $+I \subseteq r . x . s+I$

(d) a.r.s $+I \subseteq x . r . s+I$

Lemma 2.9[3]. Misalkan I merupakan Q-ideal dari semiring ternari S. Jika $x \in S$, maka terdapat $q \in Q$ sedemikian hingga $x+I \subseteq q+I$. Karenanya $x=q+a$ untuk beberapa $a \in I$.

Selanjutnya, berikut diberikan definisi mengenai semiring ternari faktor.

Definisi 2.10[3]. Misalkan I adalah Q-ideal pada semiring ternari $S$, didefinisikan dengan operasi biner $\oplus$ dan operasi terner $\odot$ pada $S / I_{(Q)}=\{q+I: q \in Q\}$ berlaku :

(a) $\left(q_{1}+I\right) \oplus\left(q_{2}+I\right)=\left(q_{3}+I\right)$ dimana $q_{1}+q_{2}+I \subseteq$ $q_{3}+I$ untuk setiap $\left(q_{1}+I\right),\left(q_{2}+I\right) \in S / I_{(Q)}$ dan $q_{1}, q_{2}, q_{3} \in Q$, serta

(b) $\left(q_{1}+I\right) \odot(r+I) \odot(s+I)=\left(q_{4}+I\right)$ dimana $q_{1} r s+$ $I \subseteq q_{4}+I$ untuk setiap $\left(q_{1}+I\right),(r+I),(s+I) \in S /$ $I_{(Q)}$ dan $q_{1}, r, s \in Q$.

\section{METODOLOGI PENELITIAN}

Metode yang digunakan dalam pengerjaan tugas akhir ini terdapat beberapa tahapan, yaitu:

\section{A. Studi Literatur}

Pada tahap ini, akan dilakukan identifikasi permasalahan dengan mempelajari konsep mengenai definisi semiring ternari, ideal pada semiring ternari, dan bentuk - bentuk ideal pada semiring ternari. Konsep tersebut dipelajari lebih mendalam melalui buku - buku literatur dan paper.
B. Mengkaji Bentuk-bentuk Ideal pada Semiring Ternari $\mathbb{Z}_{0}^{-} \times \mathbb{Z}_{0}^{-}$

Pada tahap ini, akan dikaji mengenai bentuk ideal utama, $Q$ ideal, ideal subtraktif dan ideal perluasan subtraktif pada semiring ternari $\mathbb{Z}_{0}^{-} \times \mathbb{Z}_{0}^{-}$

C. Mengkaji Ideal Perluasan Subtraktif Terkecil pada Semiring Ternari

Dalam mengkaji ideal perluasan subtraktif terkecil pada semiring ternari yang selanjutnya dikaji mengenai sifat-sifat yang berlaku di dalamnya.

D. Mengkaji Hubungan Antara Ideal Prima pada Semiring Ternari dengan Semiring Ternari Faktor

Dalam tahap ini, dikaji mengenai ideal prima pada semiring ternari dengan semiring ternari faktor.

\section{E. Penarikan Kesimpulan}

Pada tahap ini dilakukan penarikan kesimpulan berdasarkan hasil-hasil yang diperoleh dari tahap-tahap sebelumnya.

\section{ANALISIS DAN PEMBAHASAN}

Pada bagian ini dibahas mengenai bentuk ideal pada semiring ternari $\mathbb{Z}_{0}^{-} \times \mathbb{Z}_{0}^{-}$, karakteristik ideal perluasan subtraktif terkecil pada semiring ternari dan hubungan ideal prima pada semiring ternari dengan semiring ternari faktor.

\section{A. Bentuk Ideal pada Semiring Ternari $\mathbb{Z}_{0}^{-} \times \mathbb{Z}_{0}^{-}$}

Dinotasikan $\mathbb{Z}_{0}^{+} \times \mathbb{Z}_{0}^{+}=\left(\mathbb{Z}_{0}^{+},+, \cdot\right) \times\left(\mathbb{Z}_{0}^{+},+, \cdot\right)$ adalah semiring dengan penjumlahan dan perkalian pada operasi biner dan $\mathbb{Z}_{0}^{-} \times \mathbb{Z}_{0}^{-}=\left(\mathbb{Z}_{0}^{-},+, \cdot\right) \times\left(\mathbb{Z}_{0}^{-},+, \cdot\right)$ merupakan semiring ternari dengan penjumlahan pada operasi biner dan perkalian pada operasi terner. Untuk sebarang $A \subseteq \mathbb{Z}_{0}^{-} \times \mathbb{Z}_{0}^{-}$dengan $A^{*}=$ $\{(n, m):(-n,-m) \in A\}$.

Berikut merupakan bentuk ideal pada semiring ternari $\mathbb{Z}_{0}^{-} \times \mathbb{Z}_{0}^{-}$:

Lemma 3.1.1. Diberikan I merupakan himpunan bagian dari $\mathbb{Z}_{0}^{-} \times \mathbb{Z}_{0}^{-}$, dengan demikian :

(a) I adalah ideal pada $\mathbb{Z}_{0}^{-} \times \mathbb{Z}_{0}^{-}$jika dan hanya jika $I^{*}$ adalah ideal pada $\mathbb{Z}_{0}^{+} \times \mathbb{Z}_{0}^{+}$

(b) I adalah $Q$-ideal pada $\mathbb{Z}_{0}^{-} \times \mathbb{Z}_{0}^{-}$jika dan hanya jika $I^{*}$ adalah $Q^{*}$-ideal pada $\mathbb{Z}_{0}^{+} \times \mathbb{Z}_{0}^{+}$

(c) I adalah ideal subtraktif pada $\mathbb{Z}_{0}^{-} \times \mathbb{Z}_{0}^{-}$jika dan hanya jika $I^{*}$ adalah ideal subtraktif pada $\mathbb{Z}_{0}^{+} \times \mathbb{Z}_{0}^{+}$

(d) Jika $I \subseteq A$ adalah ideal pada $\mathbb{Z}_{0}^{-} \times \mathbb{Z}_{0}^{-}$, maka $A$ adalah ideal perluasan subtraktif dari I pada $\mathbb{Z}_{0}^{-} \times \mathbb{Z}_{0}^{-}$jika dan hanya jika $A^{*}$ adalah ideal perluasan subtraktif dari $I^{*}$ pada $\mathbb{Z}_{0}^{+} \times \mathbb{Z}_{0}^{+}$.

Berdasarkan Lemma 3.1.1 dan bentuk ideal pada $\mathbb{Z}_{0}^{+} \times \mathbb{Z}_{0}^{+}$, diperoleh akibat berikut :

Akibat 3.1.2[5]. Diberikan I subset dari $\mathbb{Z}_{0}^{-} \times \mathbb{Z}_{0}^{-}$, dengan demikian : 
(a) I adalah ideal pada $\mathbb{Z}_{0}^{-} \times \mathbb{Z}_{0}^{-}$jika dan hanya jika $I=J_{1} \times J_{2}$ dimana $J_{1}, J_{2}$ adalah ideal pada $\mathbb{Z}_{0}^{-}$.

(b) I adalah ideal utama pada $\mathbb{Z}_{0}^{-} \times \mathbb{Z}_{0}^{-}$jika dan hanya jika I = $J_{1} \times J_{2}$ dimana $J_{1}, J_{2}$ adalah ideal utama pada $\mathbb{Z}_{0}^{-}$.

(c) I adalah $Q$-ideal pada $\mathbb{Z}_{0}^{-} \times \mathbb{Z}_{0}^{-}$jika dan hanya jika $I=$ $J_{1} \times J_{2}$ dimana $J_{1}, J_{2}$ adalah $Q_{1}, Q_{2}$-ideal pada $\mathbb{Z}_{0}^{-}$dengan $Q=Q_{1} \times Q_{2}$.

(d) I adalah ideal subtraktif pada $\mathbb{Z}_{0}^{-} \times \mathbb{Z}_{0}^{-}$jika dan hanya jika $I=J_{1} \times J_{2}$ dimana $J_{1}, J_{2}$ adalah ideal subtraktif pada $\mathbb{Z}_{0}^{-}$.

Dari Lemma 3.1.1, Akibat 3.1.2 dan bentuk ideal pada $\mathbb{Z}_{0}^{+} \times \mathbb{Z}_{0}^{+}$, maka diperoleh akibat :

Akibat 3.1.3[5]. Diberikan I adalah ideal dari $\mathbb{Z}_{0}^{-} \times \mathbb{Z}_{0}^{-}$, maka pernyataan berikut ekivalen :

(a) I adalah ideal utama

(b) I adalah Q-ideal

(c) I adalah ideal subtraktif

Contoh 3.1.4. Misalkan himpunan $\langle-3\rangle$ dan $\langle-4\rangle$ merupakan ideal pada $\mathbb{Z}_{0}^{-}$, dimana $\langle-3\rangle=\left\{-3 m_{1} m_{2} \mid m_{1}, m_{2} \in \mathbb{Z}_{0}^{-}\right\}=$ $\left\{-3 k_{1} \mid k_{1} \in \mathbb{Z}_{0}^{+}\right\} \quad$ dan $\quad\langle-4\rangle=\left\{-4 n_{1} n_{2} \mid n_{1}, n_{2} \in \mathbb{Z}_{0}^{-}\right\}=$ $\left\{-4 k_{2} \mid k_{2} \in \mathbb{Z}_{0}^{+}\right\} \quad$ dengan $\quad Q_{1}=\{0,-1,-2\}, \quad Q_{2}=$ $\{0,-1,-2,-3\}$. Menurut Akibat 3.1.3 diperoleh :

a. $\quad I=\langle-3\rangle \times\langle-4\rangle$ merupakan ideal utama pada $\mathbb{Z}_{0}^{-} \times \mathbb{Z}_{0}^{-}$ dengan bentuk $I=\langle(-3,-4)\rangle$.

b. $\quad I=\langle-3\rangle \times\langle-4\rangle$ merupakan $Q$-ideal pada $\mathbb{Z}_{0}^{-} \times \mathbb{Z}_{0}^{-}$dengan bentuk partisi $\left(-q_{1},-q_{2}\right)+\langle-3\rangle \times\langle-4\rangle$, dimana $q_{1} \in Q_{1}$, dan $q_{2} \in Q_{2}$.

c. $I=\langle-3\rangle \times\langle-4\rangle$ adalah ideal subtraktif pada $\mathbb{Z}_{0}^{-} \times \mathbb{Z}_{0}^{-}$ dengan bentuk :

$$
\begin{aligned}
I & =\langle-3\rangle \times\langle-4\rangle \\
& =\left\{\left(-3 k_{1},-4 k_{2}\right) \mid k_{1}, k_{2} \in \mathbb{Z}_{0}^{+}\right\} .
\end{aligned}
$$

Selanjutnya, dari Lemma 3.1.1 (d) dan bentuk ideal perluasan subtraktif pada semiring $\mathbb{Z}_{0}^{+} \times \mathbb{Z}_{0}^{+}$, maka diperoleh akibat :

Akibat 3.1.5[5]. Diberikan I $\subseteq$ A adalah ideal pada semiring ternari $\mathbb{Z}_{0}^{-} \times \mathbb{Z}_{0}^{-}$. Maka A adalah ideal perluasan subtraktif jika dan hanya jika $A=A_{1} \times A_{2}$ dimana ideal $A_{i}$ adalah ideal perluasan subtraktif dari $J_{i}(i=1,2)$ pada semiring ternari $\mathbb{Z}_{0}^{-}$ dengan $I=J_{1} \times J_{2}$.

B. Ideal Perluasan Subtraktif Terkecil pada Semiring Ternari

Pada penelitian J.N Chaudhari dan K.J. Ingale [5] diperkenalkan bentuk ideal baru yaitu ideal perluasan subtraktif terkecil. Berikut diberikan beberapa notasi yang berkaitan dengan ideal perluasan subtraktif terkecil pada semiring ternari.

Diberikan $I, A$ adalah ideal pada semiring ternari $S$ yang memenuhi $I \subseteq A$, maka :

1. $\overline{A_{I}}=\{x \in S \mid x+i \in A$ untuk suatu $i \in I\}$ dinamakan tertutup dari $A$ terhadap $I$.

2. $\tilde{A}=\left\{x \in S \mid q+I \in S / I_{(Q)}\right.$ dimana $x \in q+I$ dan $(q+$ $I) \cap A \neq \emptyset\}$ dinamakan tertutup dari $A$ terhadap $I_{(Q)}$ dimana $I$ adalah $Q$-ideal pada $S$.
3. $\bar{A}=\{x \in S \mid x+y \in A$ untuk suatu $y \in A\}$ dinamakan $k$ tertutup dari $A$.

Berikut diberikan sebagai contoh :

Contoh 3.2.1. Misalkan $I=\langle-3\rangle=\left\{-3 k \mid k \in \mathbb{Z}_{0}^{+}\right\}$dan $A=$ $\langle-3,-5\rangle=\mathbb{Z}_{0}^{-}-\{-1,-2,-4,-7\}$ adalah ideal pada semiring ternari $\mathbb{Z}_{0}^{-}$, maka $I$ adalah $Q$-ideal pada semiring ternari $\mathbb{Z}_{0}^{-}$ dengan $Q=\{0,-1,-2\}$ dan $I \subseteq A$. Sehingga berbentuk :

a. $\quad I+0=I=\left\{-3 k \mid k \in \mathbb{Z}_{0}^{+}\right\}$

b. $I+-1=\left\{-3 k-1 \mid k \in \mathbb{Z}_{0}^{+}\right\}$

c. $I+-2=\left\{-3 k-2 \mid k \in \mathbb{Z}_{0}^{+}\right\}$

dan

a. $I+0 \cap A \neq \varnothing$, maka $I+0 \subseteq \widetilde{A}$

b. $I+-1 \cap A=I-1 \cap A \neq \emptyset$, maka $I+0 \subseteq \widetilde{A}$

c. $I+-2 \cap A=I-2 \bigcap A \neq \emptyset$, maka $I+0 \subseteq \widetilde{A}$

Sehingga diperoleh, $I+0 \cup I-1 \cup I-2=\mathbb{Z}_{0}^{-} \subseteq \widetilde{A}$, maka $\widetilde{A}=\mathbb{Z}_{0}^{-}$.

Selanjutnya diberikan teorema mengenai ideal perluasan subtraktif berikut :

Teorema 3.2.2. Diberikan $I \subseteq A$ adalah ideal pada semiring ternari S. Maka $\overline{A_{I}}$ adalah ideal perluasan subtraktif terkecil dari I yang memuat $A$.

Bukti :

Untuk membuktikan $\overline{A_{I}}$ adalah ideal perluasan subtraktif terkecil pada $I$ yang memuat $A$ terdapat beberapa tahap, yaitu :

1. Akan ditunjukkan bahwa $\overline{A_{I}}$ adalah ideal pada semiring ternari $S$. Maka :

Ambil $x_{1}, x_{2} \in \overline{A_{I}}$ dan $r, s \in S$, terdapat $i_{1}, i_{2} \in I$. Sedemikian hingga :

$$
x_{1}+i_{1}, x_{2}+i_{2} \in A
$$

Oleh karena $I \subseteq A$ adalah ideal pada semiring ternari $S$, maka :

$\left(x_{1}+x_{2}\right)+\left(i_{1}+i_{2}\right)=x_{1}+i_{1}+x_{2}+i_{2} \in A \quad$ dimana $i_{1}+i_{2} \in I$. Mengakibatkan $x_{1}+x_{2} \in \overline{A_{I}}$. Dengan cara yang sama terdapat $i_{1}, i_{2}, i_{3} \in I$ sehingga :

$$
\begin{aligned}
\left(r+i_{1}\right)\left(s+i_{2}\right) & \left(x_{1}+i_{3}\right) \\
& =\left(r s+r i_{2}+i_{1} s+i_{1} i_{2}\right)\left(x_{1}+i_{3}\right)
\end{aligned}
$$

$=r s x_{1}+r s i_{3}+r i_{2} x_{1}+r i_{2} i_{3}+i_{1} s x_{1}+i_{1} s i_{3}+$

$i_{1} i_{2} x_{1}+i_{1} i_{2} i_{3}$

Karena $r s i_{3}+r i_{2} x_{1}+r i_{2} i_{3}+i_{1} s x_{1}+i_{1} s i_{3}+i_{1} i_{2} x_{1}+$ $i_{1} i_{2} i_{3}$ tertutup terhadap $I$, maka :

$r s x_{1}+r s i_{3}+r i_{2} x_{1}+r i_{2} i_{3}+i_{1} s x_{1}+i_{1} s i_{3}+i_{1} i_{2} x_{1}+$ $i_{1} i_{2} i_{3} \in A$

Mengakibatkan $r s x_{1} \in \overline{A_{I}}$. Karena semiring ternari bersifat komutatif maka $r x_{1} s, x_{1} s r \in \overline{A_{I}}$. Maka terbukti $\overline{A_{I}}$ merupakan ideal pada semiring ternari $S$.

2. Secara jelas diperoleh bahwa $A \subseteq \overline{A_{I}}$. Selanjutnya akan ditunjukkan bahwa $\overline{A_{I}}$ adalah ideal perluasan subtraktif pada $I$. Maka :

Ambil $i \in I, x+i \in \overline{A_{I}}, x \in S$, terdapat $i^{\prime} \in I$ sedemikian hingga $x+i+i^{\prime} \in A$. Oleh karena $i+i^{\prime} \in I$ dan $x \in \overline{A_{I}}$, maka terbukti $\overline{A_{I}}$ merupakan ideal perluasan subtraktif pada $I$. 
3. Selanjutnya, misalkan $J$ adalah ideal perluasan subtraktif pada $I$ yang memuat $A$ dan $x \in \overline{A_{I}}$, terdapat $i \in I$ sedemikian hingga $x+i \in A \subseteq J$. Oleh karena $J$ merupakan ideal perluasan subtraktif pada $I$ maka dalam hal ini terlihat jelas bahwa $x \in J$, sehingga $\overline{A_{I}} \subseteq J$.

Dari pembahasan di atas, terbukti bahwa $\overline{A_{I}}$ merupakan ideal perluasan terkecil pada $I$ yang memuat $A$.

Berdasarkan Teorema 3.2.2, maka diperoleh akibat:

Akibat 3.2.3[5]. Diberikan I $\subseteq$ A adalah ideal pada semiring ternari $S$. Dengan demikian :

$\overline{A_{I}}=\cap\{J: J$ adalah ideal perluasan subtraktif pada I yang тетиаt $A\}$.

Teorema 3.2.4. Diberikan $I, A, B$ adalah ideal pada semiring ternari $S$, sedemikian hingga $I \subseteq A, B$. Dengan demikian :

(a) $A$ adalah ideal perluasan subtraktif pada $I \Leftrightarrow \overline{A_{I}}=A$

(b) $\overline{\left(\overline{A_{I}}\right)_{I}}=\overline{A_{I}}$.

(c) $A \subseteq B \Rightarrow \overline{A_{I}} \subseteq \overline{B_{I}}$.

(d) $\overline{(A \cap B)_{I}}=\overline{A_{I}} \cap \overline{B_{I}}$.

(e) Jika $A, B$ adalah ideal perluasan subtraktif pada I, maka $A \cap B$ adalah ideal perluasan subtraktif pada I

(f) Jika J adalah ideal pada semiring ternari $S$, sedemikian hingga $I \subseteq J \subseteq A$, maka $\overline{A_{I}} \subseteq \overline{A_{J}}$.

Dari Teorema 3.2.4 diperoleh akibat:

Akibat 3.2.5[5]. Diberikan $A, B$ adalah ideal pada semiring ternari S. Maka $\overline{A \cap B} \subseteq \bar{A} \cap \bar{B}$.

Bukti :

Perhatikan bahwa $A \cap B \subseteq A$ atau $A \cap B \subseteq B$. Dengan menggunakan teorema 3.3 (c), maka $\overline{A \cap B}=\overline{(A \cap B)_{(A \cap B)}} \subseteq$ $\overline{A_{(A \cap B)}}$ atau $\overline{A \cap B}=\overline{(A \cap B)_{(A \cap B)}} \subseteq \overline{B_{(A \cap B)}}$. Dengan mengikuti teorema 3.3(f), maka diperoleh bahwa $\overline{A_{(A \cap B)}} \subseteq \overline{A_{A}}=\bar{A}$ atau $\overline{B_{(A \cap B)}} \subseteq \overline{B_{B}}=\bar{B}$. Akibatnya, $\overline{A \cap B} \subseteq \bar{A}$ atau $\overline{A \cap B} \subseteq \bar{B}$. Dengan kata lain $\overline{A \cap B} \subseteq \bar{A} \cap \bar{B}$.

Selanjutnya diberikan lemma mengenai hubungan antara $\overline{A_{I}} \operatorname{dan} \widetilde{A}$.

Lemma 3.2.6. Diberikan I adalah Q-ideal pada semiring ternari $S$ dan $A$ adalah ideal pada $S$ dengan $I \subseteq A$. Maka $\overline{A_{I}}=$ $\widetilde{A}$. akibat:

Dari Teorema 3.2.2 dan Lemma 3.2.6, maka diperoleh

Akibat 3.2.7. Diberikan I adalah Q-ideal pada semiring ternari $S$ dan $A$ adalah ideal pada $S$ dengan $I \subseteq A$. Maka $\widetilde{A}$ adalah ideal perluasan subtraktif terkecil pada I yang mетиаt A.

Lemma 3.2.8. Diberikan I adalah Q-ideal pada semiring ternari $S$ dan $A$ adalah ideal pada $S$ dengan $I \subseteq A$. Maka $A$ adalah ideal perluasan subtraktif pada I jika dan hanya jika I adalah $Q \cap A$-ideal pada $A$.

\section{Ideal pada Semiring Ternari}

Hubungan keterkaitan antara ideal perluasan subtraktif dengan $Q$-ideal tidak hanya ada pada semiring ternari, namun juga dapat diperluas pada semiring ternari faktor. Berikut ini diberikan beberapa teorema yang menjelaskan hubungan ideal - ideal tersebut.

Teorema 3.3.1. Diberikan $I \subseteq A$ adalah ideal pada semiring ternari $S$ dan I adalah Q-ideal pada S. Dengan demikian pernyataan berikut ekivalen :

(a) A adalah perluasan subtraktif dari I

(b) I adalah $Q \cap A$-ideal dari $A$

(c) $A / I_{(Q \cap A)}$ adalah ideal pada semiring ternari $S / I_{(Q)}$.

Teorema 3.3.2. Diberikan I adalah $Q$-ideal pada semiring ternari $S$. Maka L adalah ideal pada $S / I_{(Q)}$ jika dan hanya jika terdapat $A$ adalah ideal pada $S$ sedemikian hingga $A$ adalah ideal perluasan subtraktif dari I dan $A / I_{(Q \cap A)}=L$.

\section{Bukti :}

$(\Rightarrow)$

Diketahui $L$ adalah ideal pada $S / I_{(Q)}$, maka akan ditunjukkan bahwa $A$ adalah ideal perluasan subtraktif dari $I$ $\operatorname{dan} A / I_{(Q \cap A)}=L$.

Dinotasikan :

$A=\{x \in S \mid x+I \subseteq q+I \in L$ untuk suatu $q \in Q\}$

Terlihat jelas bahwa $A \subseteq S$, selanjutnya ambil sebarang $x, y \in A$ dan $r, s \in S$. Menurut Lemma 1.9 terdapat secara tunggal $q_{1}, q_{2}, q^{\prime}, q^{\prime \prime} \in Q$ yang memenuhi $x+I \subseteq q_{1}+I \in$ $L, y+I \subseteq q_{2}+I \in L, r+I \subseteq q^{\prime}+I \in L$ dan $s+I \subseteq q^{\prime \prime}+$ $I \in L$. Oleh karena telah diketahui bahwa $L$ adalah ideal pada $S / I_{(Q)}$, maka dengan demikian :

a. $\quad\left(q_{1}+I\right) \oplus\left(q_{2}+I\right)=\left(q_{3}+I\right) \in L \quad$ dimana $\quad q_{1}+q_{2}+$ $I \subseteq q_{3}+I$ untuk suatu $q_{3} \in Q$. Dari $x+I \subseteq q_{1}+I$ dan $y+I \subseteq q_{2}+I$, diperoleh $x+I+y+I \subseteq q_{1}+I+q_{2}+$ $I$. Dikarenakan $I$ adalah ideal pada semiring ternari $S$ maka didapat $x+y+I \subseteq q_{1}+q_{2}+I$. Selanjutnya perhatikan bahwa $\quad x+y=x+y+0 \in x+I+y+I, \quad$ sehingga diperoleh $x+y \in x+y+I \subseteq q_{1}+q_{2}+I \subseteq q_{3}+I \in L$. Dengan demikian $x+y \in A$.

b. $\quad\left(q^{\prime}+I\right) \odot\left(q^{\prime \prime}+I\right) \odot\left(q_{1}+I\right)=\left(q_{4}+I\right) \in L \quad$ dimana $q^{\prime} q^{\prime \prime} q_{1}+I \subseteq q_{4}+I$ untuk suatu $q_{4} \in Q$. Oleh karena $r+$ $I \subseteq q^{\prime}+I, \quad s+I \subseteq q^{\prime \prime}+I$ dan $x+I \subseteq q_{1}+I$, maka $(r+I)(s+I)(x+I) \subseteq\left(q^{\prime}+I\right)\left(q^{\prime \prime}+I\right)\left(q_{1}+I\right)$.

Dikarenakan $I$ adalah ideal pada semiring ternari $S$, maka diperoleh $r s x+I \subseteq q^{\prime} q^{\prime \prime} q_{1}+I$. Oleh karena $r s x=r s x+$ $0 \in r s x+I$, sehingga $\quad r s x \in r s x+I \subseteq q^{\prime} q^{\prime \prime} q_{1}+I \subseteq q_{5}+$ $I \in L$. Dengan demikian $r s x \in A$. Dengan menggunakan sifat komutatif, maka diperoleh bahwa $r x s, x r s \in A$. Oleh karena memenuhi $x+y \in A$ dan $r s x, r x s, x r s \in A$ untuk sebarang $x, y \in A$ dan $r, s \in S$ maka diperoleh bahwa $A$ adalah ideal pada semiring ternari $S$. Selanjutnya ambil sebarang $a \in I$, maka diperoleh bahwa $a \in q_{0}+I \in L$ dengan $q_{0}+I$ adalah elemen nol pada ideal $L$. Sehingga $a \in A$ dan berakibat $I \subseteq A$. 
Kemudian ambil sebarang $x \in I, x+y \in A$ dan $y \in S, x \in$ $q_{0}+I$ dengan $q_{0}+I$ adalah elemen nol di $S / I_{(Q)}$. Karena $x+$ $y \in A$, maka didapat $x+y \in x+y+I \subseteq q_{6}+I \in L$. Selanjutnya karena $y \in S$, maka menurut Lemma 1.9 diperoleh bahwa $y=y+0 \in y+I \subseteq q_{7}+I$ untuk suatu $q_{7} \in Q$. Perhatikan bahwa $x+y \in\left(q_{0}+I\right) \oplus\left(q_{7}+I\right)=\left(q_{7}+I\right) \in$ $L$ dimana $\left(q_{6}+I\right) \cap\left(q_{7}+I\right) \neq \varnothing$ dan $q_{6}=q_{7}$. Dengan demikian $y \in q_{7}+I=q_{6}+I \in L$ dan mengakibatkan $y \in A$. Sehingga terbukti bahwa $A$ adalah ideal perluasan subtraktif dari $I$. Selanjutnya akan dibuktikan bahwa $A / I_{(Q \cap A)}=L$. Didefinisikan bahwa $A / I_{(Q \cap A)}=\{x+I \mid x \in Q \cap A\}$. Ambil sebarang $x+I \in A / I_{(Q \cap A)}$ dimana $x \in Q \cap A \subseteq A$, maka dengan demikian $x \in x+I \subseteq q_{8}+I \in L$ untuk suatu $q_{8} \in Q$. Akibatnya $A / I_{(Q \cap A)} \subseteq L$. Di sisi lain, ambil sebarang $q_{9}+I \in$ $L$ untuk suatu $q_{9} \in Q$, akan ditunjukkan $q_{9}+I \in A / I_{(Q \cap A)}$. Oleh karena $q_{9} \in S$ dan $q_{9}+I \subseteq q_{9}+I \in L$, maka $q \in A$, akibatnya $q \in Q \cap A$ sehingga $q_{9}+I \in A / I_{(Q \cap A)}$. Dengan kata lain terbukti bahwa $A / I_{(Q \cap A)}=L$.

$(\Leftarrow)$

Akan ditunjukkan bahwa $L$ adalah ideal pada $S / I_{(Q)}$. Oleh karena $A$ adalah ideal perluasan subtraktif dari $I$ dan berlaku bahwa $A / I_{(Q \cap A)}=L$, maka menurut Teorema 3.3.1, diperoleh bahwa $L$ adalah ideal pada $S / I_{(Q)}$.

Teorema 3.3.3. Diberikan $S$ adalah semiring ternari, I adalah $Q$-ideal pada $S$ dan $P$ adalah ideal perluasan subtraktif dari I, maka $P$ adalah ideal prima pada $S$ jika dan hanya jika $P$ / $I_{(Q \cap P)}$ adalah ideal prima pada $S / I_{(Q)}$.

\section{Bukti :}

$(\Rightarrow)$

Diketahui bahwa $P$ adalah ideal prima pada $S$. Akan ditunjukkan bahwa ideal $P / I_{(Q \cap P)}$ adalah ideal prima pada $S$ / $I_{(Q)}$. Ambil sebarang $q_{1}+I, q_{2}+I, q_{3}+I \in S / I_{(Q)}$ dengan $q_{1}, q_{2}, q_{3} \in Q$, yang memenuhi $\left(q_{1}+I\right) \odot\left(q_{2}+I\right) \odot\left(q_{3}+\right.$ $I)=\left(q_{4}+I\right) \in P / I_{(Q \cap P)} \quad$ untuk suatu $q_{4} \in Q \cap P$ adalah elemen tunggal, sedemikian hingga $q_{1} q_{2} q_{3}+i_{1}=q_{4}+i_{2} \in$ $P$, untuk suatu $i_{1}, i_{2} \in I$. Dikarenakan ideal $P$ adalah ideal perluasan subtraktif dari $I$ dan $q_{1} q_{2} q_{3}+i_{1} \in P$ maka diperoleh $q_{1} q_{2} q_{3} \in P$. Selanjutnya, oleh karena ideal $P$ adalah ideal prima pada semiring ternari $S$, maka diperoleh $q_{1} \in P$ atau $q_{2} \in$ $P$ atau $q_{3} \in P$. Oleh karena itu $q_{1} \in Q \cap P$ atau $q_{2} \in Q \cap P$ atau $q_{3} \in Q \cap P$ dan diperoleh bahwa $q_{1}+I \in P / I_{(Q \cap P)}$ atau $q_{2}+$ $I \in P / I_{(Q \cap P)}$ atau $q_{3}+I \in P / I_{(Q \cap P)}$. Dengan demikian terbukti bahwa ideal $P / I_{(Q \cap P)}$ adalah ideal prima pada semiring ternari $S / I_{(Q)}$.

$(\Leftarrow)$

Akan ditunjukkan bahwa ideal $P$ adalah ideal prima pada semiring ternari $S$. Ambil sebarang $a b c \in P$ dimana $a, b, c \in S$. Telah diketahui bahwa $I$ adalah $Q$-ideal pada semiring ternari $S$, dengan demikian terdapat secara tunggal $q_{1}, q_{2}, q_{3}, q_{4} \in Q$ yang memenuhi $a \in q_{1}+I, b \in q_{2}+I$ dan $c \in q_{3}+I$ dan $a b c \in\left(q_{1}+I\right) \odot\left(q_{2}+I\right) \odot\left(q_{3}+I\right)=\left(q_{4}+I\right) \quad$ dimana $q_{1} q_{2} q_{3}+I \subseteq q_{4}+I$. Oleh karena $a b c \in q_{4}+I$, maka berlaku $a b c=q_{4}+i$ untuk suatu $i \in I$. Selanjutnya, oleh karena $a b c \in$
$P$, maka diperoleh $q_{4}+i \in P$ untuk suatu $i \in I$. Telah diketahui sebelumnya bahwa $P$ adalah ideal perluasan subtraktif dari $I$, maka diperoleh bahwa $q_{4} \in P$, sehingga $q_{4} \in$ $Q \cap P$ dan berakibat $q_{4}+I \in P / I_{(Q \cap P)}$. Dikarenakan ideal $P /$ $I_{(Q \cap P)}$ adalah ideal prima pada semiring ternari $S / I_{(Q)}$, maka $\left(q_{1}+I\right) \odot\left(q_{2}+I\right) \odot\left(q_{3}+I\right)=\left(q_{4}+I\right) \in P / I_{(Q \cap P)}$.

Dengan demikian, diperoleh $a \in q_{1}+I \in P / I_{(Q \cap P)}$ atau $b \in$ $q_{2}+I \in P / I_{(Q \cap P)} \quad$ atau $\quad c \in q_{3}+I \in P / I_{(Q \cap P)}$ dimana $q_{1}, q_{2}, q_{3} \in Q \cap P$. Sehingga berlaku bahwa $a=q_{1}+i_{1}$ atau $b=q_{2}+i_{2}$ atau $c=q_{3}+i_{3}$ untuk suatu $i_{1}, i_{2} i_{3} \in I$. Di sisi lain, oleh karena ideal $P$ adalah ideal pada semiring ternari $S$ maka diperoleh $q_{1}+i_{1} \in P$ atau $q_{2}+i_{2} \in P$ atau $q_{3}+i_{3} \in P$. Akibatnya, $a \in P$ atau $b \in P$ atau $c \in P$. Sehingga terbukti bahwa ideal $P$ adalah ideal prima pada semiring ternari $S$.

\section{KESIMPULAN DAN SARAN}

\section{A. Kesimpulan}

Dari analisis dan pembahasan yang telah disajikan pada bab sebelumnya, dapat disimpulkan beberapa hal sebagai berikut:

1. Bentuk-bentuk ideal pada semiring ternari $\mathbb{Z}_{0}^{-} \times \mathbb{Z}_{0}^{-}$yaitu :

(a) Terdapat hubungan antara bentuk ideal, ideal utama, $Q$-ideal, dan ideal subtraktif pada $\mathbb{Z}_{0}^{+} \times \mathbb{Z}_{0}^{+}$dengan $\mathbb{Z}_{0}^{-} \times \mathbb{Z}_{0}^{-}$.

(b) Bentuk dari ideal utama, $Q$-ideal, ideal subtraktif, dan ideal perluasan subtraktif pada semiring ternari adalah ekivalen.

2. Karakteristik mengenai ideal perluasan subtraktif terkecil pada semiring ternari yaitu:

(a) Jika $I \subseteq A$ adalah ideal pada semiring ternari $S$, maka $\overline{A_{I}}$ adalah ideal perluasan subtraktif terkecil dari $I$ yang memuat $A$.

(b) Jika $I$ adalah $Q$-ideal pada semiring ternari $S$ dan $A$ adalah ideal pada $S$ dengan $I \subseteq A$, maka $\overline{A_{I}}=\widetilde{A}$.

3. Jika $I$ adalah $Q$-ideal pada semiring ternari $S$ dan $P$ adalah ideal perluasan subtraktif dari $I$, maka $P$ adalah ideal prima pada $S \Leftrightarrow P / I_{(Q \cap P)}$ adalah ideal prima pada $S / I_{(Q)}$.

\section{B. Saran}

Pada jurnal ini hanya membahas tentang semiring ternari faktor pada ideal prima. Oleh karena itu, penulis menyarankan agar penelitian selanjutnya bisa melakukan pembahasan terhadap ideal semiprima, prima lemah, primari dan primari lemah, ataupun terhadap bentuk ideal pada semiring ternari lainnya.

\section{UCAPAN TERIMA KASIH}

Penyelesaian dalam kajian ini tidak lepas dari orang-orang terdekat yang telah mendukung dan memotivasi penulis. Oleh sebab itu, penulis mengucapkan terima kasih kepada kedua orang tua penulis yang senantiasa memberikan dukungan , motivasi dan do'a serta Kementerian Agama NKRI yang telah memberikan dukungan finansial melalui beasiswa Penerimaan Beasiswa Santri Berprestasi tahun 2012-2016. Penulis juga 
menyampaikan ucapan terima kasih kepada seluruh dosen pengajar dan karyawan di Institut Teknologi Sepuluh Nopember, khususnya di Jurusan Matematika FMIPA ITS yang telah memberikan ilmu kepada penulis.

\section{DAFTAR PUSTAKA}

[1] W.G. Lister. (1971). "Ternary Rings". Transactions of The American Mathematical Society Vol. 154, Hal.37-55..

[2] T.K. Dutta, S. Kar. (2003). "On Regular Ternary Semirings". Advances in Algebra Proceedings of The ICM Satellite Conference in Algebra and Related Topics, World Scientific, Hal. 343-355.

[3] J.N. Chaudhari, K.J. Ingale. (2011). "On Partioning and Subtractive Ideals of Ternary Semirings". Kyungpook Math. Journal 51(1), Hal.69-76.

[4] S. Kar. (2011). "Ideal Theory in The Ternary Semirings $\mathbb{Z}_{0}^{-}$". Bull. Malays. Math. Scientific. Society (2) 34 (1), Hal.69-77.

[5] J.N Chaudhari, K.J. Ingale. (2016). "Subtractive Extension of Ideals in Ternary Semirings". Thai Journal of Mathematics.

[6] J.N Chaudhari, D.R Bonde (2014). "Ideal Theory in Quotient Semirings". Thai Journal of Mathematics Vol. 12 (1), Hal.95-101.

[7] Atani, S.E. (2007). "The Ideal Theory in Quotient of Commutative Semirings". Glasnik Matematicki Vol. 42(62), Hal. 301-308. 